\title{
Blood Volume Regulation
}

\author{
Roland E. Winkler ${ }^{1}$, Fabio Grandi ${ }^{2}$ and Antonio Santoro ${ }^{3}$ \\ ${ }^{1}$ Department Nephrology and Dialysis-PDA Rostock \\ ${ }^{2}$ Gambro S.p.A. \\ ${ }^{3}$ Department of Nephrology, Dialysis and Hypertension \\ Policlinico S. Orsola-Malpighi \\ ${ }^{1}$ Germany \\ 2,3Italy
}

\section{Introduction}

Cardiovascular death remains the most frequent cause of mortality of dialysis population. Among the risk factor of cardiovascular mortality low blood pressure has been investigated by several authors even though not all the author conclude that low blood pressure per se, not adjusted for concomitant factors like age, and the presence of diabetes can be seen as independent predictor of mortality (Tisler et al., 2003; Iseki et al., 1997; Port et al., 1999).

In particular, the presence of low blood pressure and the intradialytic fall in the systolic and diastolic blood pressure seems to predict mortality in the dialysis population (Sohji et al., 2004). Some other authors found that not only low predialysis systolic blood pressure but also high values (J shape theory) expose patients at higher risk of mortality (Port et al, 1999). Nevertheless, the fall in systolic blood pressure seems to be to date the most common intradialytic complication accounting for up to $30 \%$ of dialysis related symptoms, despite the several improvement of dialysis techniques in terms of biocompatibility of the material used, more convection and quality of dialysis fluid. But hypertension is indeed the most frequent chronic co morbidity affecting dialysis patients.

Predialysis hypertension does not prevent hypotension episodes and not having targets for blood pressure control will not necessarily reduce its onset. When improved control of blood pressure is desired, modifications to the dialysis treatment itself should be considered as part of the management strategy (Davenport et al., 2008).

Hypo- as well hypertension are then the most challenging complications which dialysis has to face with. Several strategies are available to prevent hypo and hypertension like longer or more frequent dialysis regimen, diffusive-convective therapies, and assessment of dry body weight. Not all of them can be used in routine practice due to infrastructural or financial constraints while some others give in a certain extent opposite's effects like assessment of dry body weight beneficial for the hypertensive status, but which can lead to an increase of intradialytic symptoms (Davenport et al., 2008). Among the tools today available, the biofeedback systems, those devices able to adapt the operative condition of dialysis to the dynamic changes of the patients status along the dialysis, seems to be promising for contributing a step forward in the patients well-being (Locatelli et al., 2005) Among these devices the Hemocontrol Biofeedback System (HBS) has been extensively studied by several 
authors as a tool to contribute in lowering the hypotension incidence but also as a further utility to control or normalize the blood pressure.

This review will summarize all the contributions given by the several studies about the cardiovascular stability in HBS dialysis.

\section{HemocontrolTM biofeedback system}

It is well known that blood volume behavior during dialysis is affected by several factors among which the ultrafiltration and changes in dialysate sodium level are the most relevant. Ultrafiltration should be adapted to the rhythm of plasma water removal respect to the patient's refilling capabilities, but the main limitation relies in the inability to maintain the total planned weight loss within the preset dialysis time except for long lasting dialysis treatments. The dialysate sodium can also promote the mobilization of water from the extravascular space reconstituting the plasma lost during ultrafiltration. Moreover, the modification of the intravascular sodium level can increase the activity of the autonomic nervous system, with a better hemodynamic response from the peripheral vascular resistance. However, the intradialytic sodium balance must be taken under tight control to avoid any sodium overload leading in turn a fluid overload especially in the interdialytic period. The blood volume control system (Hemocontrol) has been developed bearing in mind these three aspects (hemodynamic stability, fluid and sodium balance). The system is designed as feedback controller with three controlled variables (blood volume, total weight loss and average dialysate sodium level) and two actuators, the ultrafiltration and actual dialysate sodium level (Paolini \& Bosetto, 1999) (Figure 1).

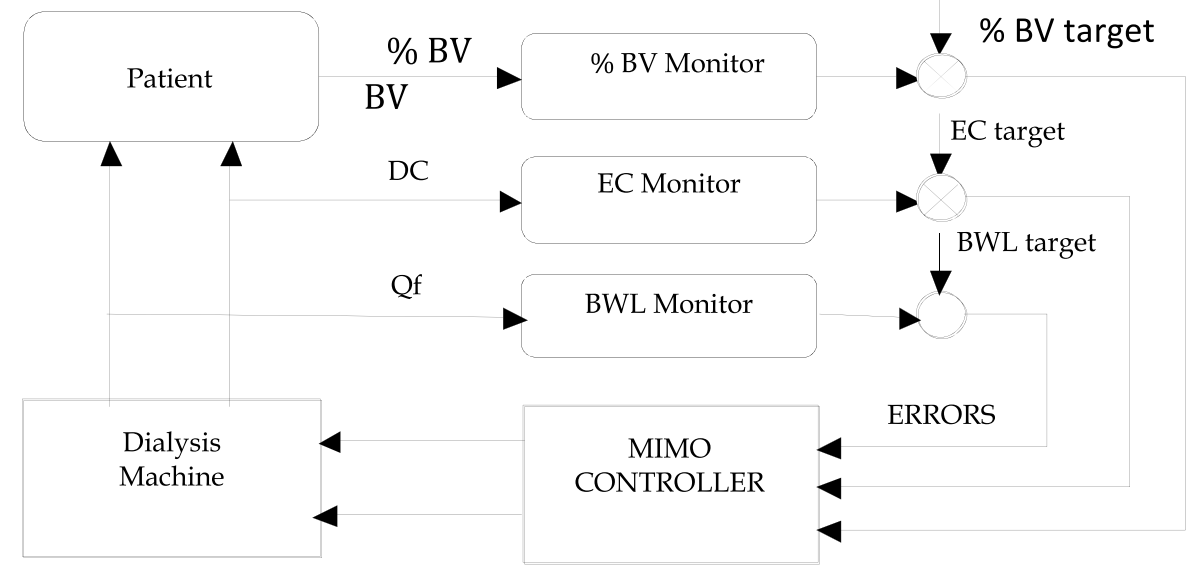

Fig. 1. Schematic representation of the Hemocontrol Biofeedback System. The MIMO controller processes three different controlled variables (blood volume reduction, average dialysate conductivity, body weight loss) through the errors between the actual and the desired values. The two actuators, reacting to the errors, are the actual dialysate conductivity and the weight loss rate (Santoro et al., 1998).

In Particular, the multi-input multi-output controller processes the errors between the actual continuously measured values of BV, weight loss and average dialysate sodium and their desired values, and reacts by adjusting the ultrafiltration and actual dialysate 
sodium to keep all the controlled variables as close to the target values as possible, however within pre-specified degree of tolerance. The desired blood volume reduction is set according to the total amount of fluid to be removed during dialysis (BV/UF volume). In fact, the blood volume reduction is a function of the overall water removal (Mancini et al, 1995), then its reduction per liters of water removal should be an invariant for any patient and then can take into account for the long or short interdialytic period. Since the actual dialysate sodium level is adjusted from the controller to regulate the blood volume time pattern, another parameter is set at the beginning of dialysis, that is the average dialysate sodium level. This value must prevent any sodium overload or abrupt depletion during the treatment (Moret et al., 2002).

All the actuators, that is the ultrafiltration and actual dialysate sodium, are always limited within safety operating regions. In particular the ultrafiltration rate is upper limited from the max UF rate at the beginning of dialysis to the average weight loss rate at the end and it is lower limited by the minimum UF rate $(100 \mathrm{~mL} / \mathrm{h})$. The maximal initial UF rate is prescribed by the nurse according to patients characteristics and it is usually set at a value $20 \%$ to $50 \%$ higher than the average UF rate. The dialysate sodium is again upper limited from a maxi initial sodium content to the lowest value at the end of the treatment and the user can set the most appropriate range for the patients (Figure 2).
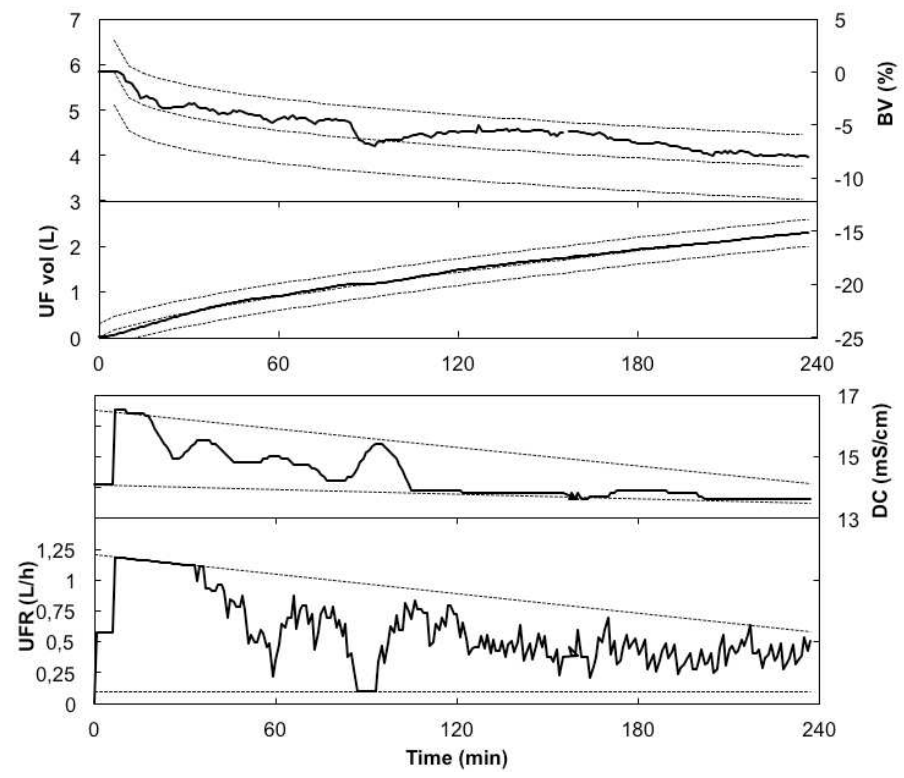

Fig. 2. Example of a HBS dialysis. The time course of the controlled variables (BV, \%, UF volume, L), are shown on the top panel, while the actuators $(\mathrm{DC}, \mathrm{mS} / \mathrm{cm}$ and Ultrafiltration rate rate, $\mathrm{L} / \mathrm{h}$ ) are shown at the bottom. According to the desired BV and UF vol time pattern (the dashed mid line in 1 and 2) the UFR and DC are adjusted time by time by the controller to minimize the error between the desired and actual values. At any time their maximum and minimum values are maintained within safety limits (dashed lines in the bottom panel) As long as the BV, UF Vol and average DC are within the pre-set tolerances (dashed lines in the top panel) there is no need to change any set-point (Santoro et al., 2002). 


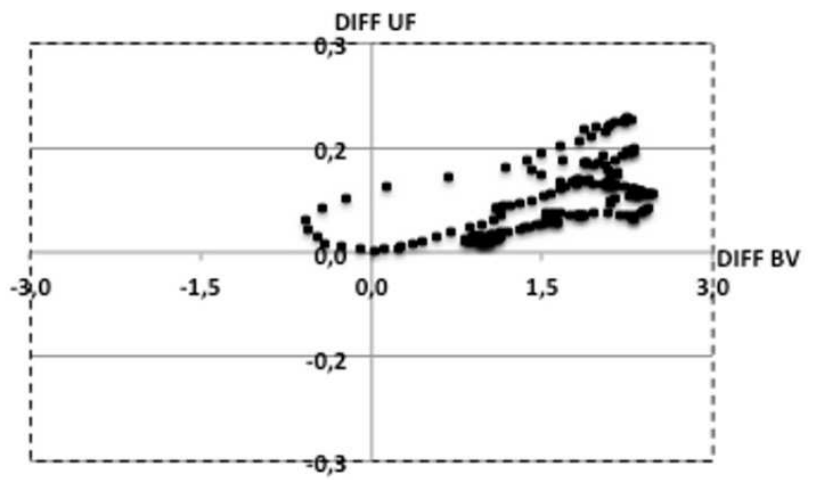

Fig. 3. State diagram of two out of the three controlled variables (BV and UF vol) during the sample dialysis shown in figure 2.

Thanks to the continuous adjustment of these parameters according to the dynamically changing clinical condition of the patient, the system is also useful to understand the refilling capacity of the patients. In fact, it can display the deviation from the set and forecasted end dialysis values respectively of the blood volume and UF volume to their set points (Figure 3). In particular, the diagram shows, on the horizontal axis, the difference between the forecasted end-dialysis BV and its set-point at any minute, while, on the vertical axis the difference between the forecasted end-dialysis UF volume and its set-point at any minute. It is worth to note that the deviation between the forecasted and set-point lies almost always in the upper right quadrant of the diagram. In this case, despite a forecasted higher UF volume, the blood volume does not fall down correspondingly, meaning that the patient's refilling capacity is higher than expected. On the contrary, when the state vector is in the lower left quadrant, the patient's refilling capacity seems to be less than expected How much this can be attributable to the hydration status (over-hydration or underhydration) is still matter of discussion even though there should be a physiological dependency behind.

\section{Clinical studies on the hemocontrol ${ }^{\mathrm{TM}}$ biofeedback system}

Since the first appearance of an abstract talking about the blood volume monitoring and control in the far 1991 Santoro et al., 1991, several studies and papers have been undertaken and written. The overall body of this literature is reported in Table 1.

Many of them are studies showing the clinical benefit of HBS in particular in the reduction of hypotension events, some others have been published to explain the underlying mechanisms for such a kind of results (Cavalcanti et al, 2004, Severi et al, 2006). We will review the results of original clinical trials, which are summarized in Table 2.

Fifteen studies were prospective, randomised, controlled trials lasting from four weeks to 48 weeks. In general, study objectives addressed haemodynamic stability during dialysis, cardiovascular effects, dialysis efficiency, interdialytic events and quality-of-life aspects. In total, the HBS has been used in more than 280 patients who were hypertensive, hypotensionprone or non-hypotension-prone. The studies were run in Canada and several European countries. Actually, 287 patients were treated in the demonstrated clinical studies, ratio between male and female was 2.2, the mean age 66.3 years $+/-6.3$ years. Diabetes mellitus was 
observed in $32.16 \%$ of all patients, Glomerulonephritis in $29.03 \%$, interstitial nephropathy $14.3 \%$, IgA nephropathy $7.1 \%$, chronic pyelonephritis $3.6 \%$, other $13.81 \%$.

\begin{tabular}{|c|c|c|c|}
\hline Author & Year & Journal & $\begin{array}{c}\text { Type of } \\
\text { publication }\end{array}$ \\
\hline Santoro A et al & 1994 & ASAIO Trans & Clinical Trial \\
\hline Santoro A & 1995 & Nephrol Dial Transplant & Editorial \\
\hline Mancini E et al & 1995 & Int J Artif Organs & Clinical Trial \\
\hline Santoro A et al & 1996 & Nephrol Dial Transplant & Review \\
\hline Santoro A et al & 1997 & Int J Artif Organs & Editorial \\
\hline Santoro A et al & 1998 & Am J Kidney Dis & Clinical Trial \\
\hline Santoro A et al & 1998 & Nephrol Dial Transplant & Review \\
\hline Paolini F et al & 1999 & Adv Ren Replace Ther & Review \\
\hline Ronco C et al & 2000 & Kidney Int & Clinical Trial \\
\hline Basile C et al & 2001 & Nephrol Dial Transplant & Clinical Trial \\
\hline Zucchelli P et al & 2001 & Semin Nephrol & Review \\
\hline Begin $\mathrm{V}$ et al & 2002 & ASAIO J & Clinical Trial \\
\hline Pastore C et al & 2002 & EDTNA ERCA J & Clinical Trial \\
\hline Santoro A et al & 2002 & Contrib Nephrol & Review \\
\hline Santoro A et al & 2002 & Kidney Int & Clinical Trial \\
\hline Wolkotte C et al & 2002 & Nephron & Clinical Trial \\
\hline McIntyre CW et al & 2003 & Clin Nephrol & Clinical Trial \\
\hline Santoro A et al & 2003 & J Nephrol & Review \\
\hline Cavalcanti $S$ et al & 2004 & Kidney Int & Clinical Trial \\
\hline Franssen CF et al & 2005 & Hemodial Int & Clinical Trial \\
\hline Selby NM et al & 2006 & Am J Kidney Dis & Clinical Trial \\
\hline Moret K et al & 2006 & Nephrol Dial Transplant & Clinical Trial \\
\hline Severi $S$ et al & 2006 & Hemodial Int & Clinical Trial \\
\hline Dasselaar JJ et al & 2007 & ASAIO J & Clinical Trial \\
\hline Dasselaar JJ et al & 2007 & J Ren Care & Clinical Trial \\
\hline Deziel C et al & 2007 & Clin J Am Soc Nephrol & Clinical Trial \\
\hline Azar AT & 2008 & Saudi J Kidney Dis Transpl & Review \\
\hline McIntyre CW et al & 2008 & Clin J Am Soc Nephrol & Clinical Trial \\
\hline Nesrallah GE et al & 2008 & ASAIO J & Clinical Trial \\
\hline Santoro A et al & 2008 & Contrib Nephrol & Review \\
\hline Winkler RE et al & 2008 & Contrib Nephrol & Clinical Trial \\
\hline
\end{tabular}

Table 1. Full list of peer reviewed papers on HBS. 


\begin{tabular}{|c|c|c|c|c|}
\hline Author & Patients & Study Design & $\begin{array}{l}\text { Major Results with HBS } \\
\text { Compared to HD }\end{array}$ & $P$ \\
\hline $\begin{array}{l}\text { Santoro } \\
\text { et al, } \\
1994 \\
\end{array}$ & $\begin{array}{l}\text { hypotension } \\
\text { prone } \\
n=5\end{array}$ & $\begin{array}{l}\text { Prospective, cross-over } \\
\text { HD(2wks) - HBS(2wks) - } \\
\text { HD(2wks) }\end{array}$ & $\begin{array}{l}\text { Intradialytic } \\
\text { hypotension } \downarrow \\
\text { Intradialytic symptoms } \downarrow\end{array}$ & $\begin{array}{l}<0.05 \\
\text { n.s. }\end{array}$ \\
\hline $\begin{array}{l}\text { Santoro } \\
\text { et al., } \\
1998^{1}\end{array}$ & $\begin{array}{l}\text { hypotension- } \\
\text { prone } \\
n=8\end{array}$ & $\begin{array}{l}\text { Prospective, cross-over } \\
\text { HD(4wks)-HBS(4wks)-HD }(4 \\
\text { wks })\end{array}$ & $\begin{array}{l}\text { intradialytic stability (SAP) } \\
\text { hypotensive episodes } \downarrow \\
\text { intradialytic events } \downarrow \\
\text { isotonic saline } \downarrow\end{array}$ & $\begin{array}{l}<0.05 \\
<0.05 \\
- \\
<0.05\end{array}$ \\
\hline $\begin{array}{l}\text { Ronco et } \\
\text { al., } 2000^{2}\end{array}$ & $\begin{array}{l}\text { hypotension- } \\
\text { prone } \\
n=12\end{array}$ & $\begin{array}{l}\text { Prospective RCT, cross-over } \\
\text { HD(2wks)-HBS(2wks) vs. } \\
\text { HBS(2wks)-HD(2wks) }\end{array}$ & $\begin{array}{l}\text { hypotensive episodes } \downarrow \\
\text { saline infusions } \downarrow \\
\text { rebound } \downarrow(\mathrm{eKt} / \mathrm{V} \uparrow)\end{array}$ & $\begin{array}{l}<0.001 \\
<0.001 \\
<0.001 \\
\end{array}$ \\
\hline $\begin{array}{l}\text { Basile et } \\
\text { al., } 2001^{3}\end{array}$ & $\begin{array}{l}\text { hypotension- } \\
\text { prone } \\
n=19\end{array}$ & $\begin{array}{l}\text { Prospective, cross-over } \\
\operatorname{HD}(6 \mathrm{mo})-\mathrm{HBS}(14-30 \mathrm{mo})- \\
\mathrm{HD}\left(4^{*}+3 \mathrm{wks}\right)-\mathrm{HBS}\left(4^{*}+3 \mathrm{wks}\right)\end{array}$ & $\begin{array}{l}\text { symptomatic } \\
\text { hypotension } \downarrow \\
\text { muscle cramps } \downarrow \\
\text { post-HD-asthenia } \downarrow \text { (other } \\
\text { symptoms n.s.) } \\
\text { vascular refilling } \downarrow\end{array}$ & $\begin{array}{l}<0.002 \\
<0.02 \\
<0.0001 \\
<0.05\end{array}$ \\
\hline $\begin{array}{l}\text { Bégin et } \\
\text { al., } 2002^{4}\end{array}$ & $\begin{array}{l}\text { hypotension- } \\
\text { prone } \mathrm{n}=7\end{array}$ & $\begin{array}{l}\text { Prospective, cross-over } \\
3 x[\mathrm{HD}(2 \mathrm{wks})-\mathrm{HBS}(2 \mathrm{wks})]\end{array}$ & $\begin{array}{l}\text { event-free sessions } \uparrow \\
\text { mean postdialysis BP } \uparrow \\
\end{array}$ & $\begin{array}{l}<0.01 \\
\end{array}$ \\
\hline $\begin{array}{l}\text { Wolkotte } \\
\text { et al., } \\
2002\end{array}$ & $\begin{array}{l}\text { Unselected } \\
\text { sample } \\
\mathrm{N}=16\end{array}$ & $\begin{array}{l}\text { Prospective, cross-over } \\
\text { HD(3wks) - HBS(3wks) }\end{array}$ & $\begin{array}{l}\text { Intradialytic } \\
\text { hypotension } \downarrow \\
\text { Intradialytic } \\
\text { symptoms } \downarrow\end{array}$ & $\begin{array}{l}0.033 \\
0.039\end{array}$ \\
\hline \begin{tabular}{|l|} 
Santoro \\
et al., \\
$2002^{5}$ \\
\end{tabular} & $\begin{array}{l}\text { hypotension- } \\
\text { prone } \\
n=36\end{array}$ & $\begin{array}{l}\text { Prospective RCT, cross-over } \\
2 x[H D(4 w k s)-H B S(4 w k s)] \text { vs. } \\
2 x[H B S(4 w k s)-H D(4 w k s)] \\
\end{array}$ & $\begin{array}{l}\text { intradialytic } \\
\text { hypotension } \downarrow \\
\text { interdialysis symptoms } \downarrow\end{array}$ & $\begin{array}{l}0.004 \\
<0.001\end{array}$ \\
\hline $\begin{array}{l}\text { McIntyre } \\
\text { et al., } \\
2003^{6}\end{array}$ & $\begin{array}{l}\text { non- } \\
\text { hypotension- } \\
\text { prone } \\
\text { n=15 }\end{array}$ & $\begin{array}{l}\text { Prospective, cross-over } \\
\text { HD(3wks)-HBS }\left(2^{*}+3 w k s\right)\end{array}$ & $\begin{array}{l}\text { symptomatic episodes } \downarrow \\
\text { reductions in systolic BP } \downarrow \\
\text { RBV falling }>10 \% \downarrow \\
\text { interdialytic weight gain } \downarrow \\
\text { eKt } / \mathrm{V} \uparrow \text {, urea clearance } \uparrow\end{array}$ & $\begin{array}{l}<0.001 \\
- \\
<0.001 \\
0.009 \\
<0.01\end{array}$ \\
\hline $\begin{array}{l}\text { Franssen } \\
\text { et al., } \\
2005^{7}\end{array}$ & $\begin{array}{l}\text { hypotension- } \\
\text { prone } \\
n=7\end{array}$ & $\begin{array}{l}\text { Prospective, cross-over } \\
\text { HD }(3 w k s)-H B S(3 w k s)-H B S( \\
6 w k s)^{1}\end{array}$ & $\begin{array}{l}\text { intradialytic hypotension } \downarrow \\
\text { systolic BP } \uparrow \\
\text { no effect on post-HD dry } \\
\text { weight }\end{array}$ & $\begin{array}{l}<0.01 \\
<0.05\end{array}$ \\
\hline $\begin{array}{l}\text { Moret et } \\
\text { al., } 2006^{8}\end{array}$ & $\begin{array}{l}\text { hypotension- } \\
\text { prone } \mathrm{n}=12\end{array}$ & $\begin{array}{l}\text { Prospective RCT, cross-over } \\
4 \text { phases: HD, HBS, SP\$, } \mathrm{PC}^{\# 2}\end{array}$ & $\begin{array}{l}\text { hypotensive episodes least } \\
\text { frequent with HBS }\end{array}$ & n.s. \\
\hline $\begin{array}{l}\text { Selby et } \\
\text { al., } 2006^{9}\end{array}$ & $\begin{array}{l}\text { hypotension- } \\
\text { prone } \\
n=8\end{array}$ & $\begin{array}{l}\text { Prospective RCT, cross-over } \\
\text { HD }\left(1^{*}+2 w k s\right)-H B S\left(1^{*}+2 w k s\right) \\
\text { vs. } \\
\text { HBS }\left(1^{*}+2 w k s\right)-H D\left(1^{*}+2 w k s\right)\end{array}$ & $\begin{array}{l}\text { LV regional wall motion } \\
\text { abnormalities } \downarrow \\
\text { EF } \uparrow \\
\text { haemodynamic data } \uparrow\end{array}$ & $\begin{array}{l}- \\
0.043 \\
<0.05\end{array}$ \\
\hline $\begin{array}{l}\text { Dasselaar } \\
\text { et al., } \\
200710\end{array}$ & $\begin{array}{l}\text { hypertensive } \\
n=28\end{array}$ & $\begin{array}{l}\text { Prospective RCT } \\
\operatorname{HD}\left(4^{*}+12 w k s\right) \text { vs. } \\
\text { HBS }\left(4^{*}+12 w k s\right)\end{array}$ & $\begin{array}{l}\text { hypotensive episodes } \downarrow \\
\text { brain natriuretic peptide } \\
\text { levels } \downarrow \\
\text { predialysis systolic BP } \downarrow\end{array}$ & $\begin{array}{l}<0.05 \\
\text { n.s. } \\
<0.05\end{array}$ \\
\hline
\end{tabular}




\begin{tabular}{|c|c|c|c|c|}
\hline Author & Patients & Study Design & $\begin{array}{l}\text { Major Results with HBS } \\
\text { Compared to HD }\end{array}$ & $P$ \\
\hline $\begin{array}{l}\text { Déziel et } \\
\text { al., } 200711\end{array}$ & \begin{tabular}{|l|}
$\sim 50 \%$ \\
hypotension- \\
prone $\sim 50 \%$ \\
hypertensive \\
$n=36$
\end{tabular} & $\begin{array}{l}\text { Prospective RCT } \\
\text { HD }\left(4 w_{k s}^{*}+6 \mathrm{mo}\right) \text { vs. } \\
\text { HBS }\left(4 w_{k s}^{*}+6 \mathrm{mo}\right)\end{array}$ & $\begin{array}{l}\text { systolic and diastolic BP } \downarrow \\
\text { intradialytic interventions } \downarrow \\
\text { QoL/KDQOL-SF (burden } \\
\text { of kidney disease) } \uparrow\end{array}$ & \begin{tabular}{|l|} 
n.s. \\
0.04 \\
0.004
\end{tabular} \\
\hline $\begin{array}{l}\text { Nesrallah } \\
\text { et al., } \\
2008^{12}\end{array}$ & $\begin{array}{l}\text { hypotension- } \\
\text { prone } \\
n=60\end{array}$ & $\begin{array}{l}\text { Prospective RCT } \\
\text { HD }\left(4 w_{k s}^{*}+6 \mathrm{mo}\right) \text { vs. } \\
\text { HBS }\left(4 \mathrm{wks}^{*}+6 \mathrm{mo}\right)\end{array}$ & $\begin{array}{l}\text { no change in extracellular } \\
\text { fluid volume } \\
\text { intradialytic hypotension } \downarrow \\
\text { no change in QoL/ dialysis- } \\
\text { related symptoms quest. }\end{array}$ & $\begin{array}{l}- \\
0.04 \\
-\end{array}$ \\
\hline $\begin{array}{l}\text { Winkler } \\
\text { et al., } \\
2008^{13}\end{array}$ & $\begin{array}{l}\text { hypotension- } \\
\text { prone } \\
n=18\end{array}$ & $\begin{array}{l}\text { Retrospective } \\
\text { HD-HBS(48wks) }\end{array}$ & $\begin{array}{l}\text { hypotensive episodes } \downarrow \\
\text { muscle cramps } \downarrow \\
\text { eKt } / \uparrow \\
\text { LVMI } \downarrow \\
\text { EF } \uparrow \\
\text { Antihypertensive drugs } \downarrow\end{array}$ & $\begin{array}{l}<0.01 \\
<0.01 \\
<0.05 \\
<0.01 \\
\text { n.s } \\
\text { n.s }\end{array}$ \\
\hline
\end{tabular}

*wash-out/run-in phase; § SP, sodium profiling; \# PC, plasma conductivity controlled feedback; $\downarrow$, reduced; $\uparrow$, improved

1) during first HBS phase post-HD weight remained stable, during second phase reduced target weight

2) 11 consecutive treatments for each modality followed by 1 week of treatment with standard dialysis Abbreviations: RCT, randomised controlled trial; HD: haemodialysis; HBS: Hemocontrol ${ }^{\mathrm{TM}}$ biofeedback system; SAP, systolic arterial blood pressure; n.s., not significant; BP, blood pressure, LV(MI), left ventricular (mass index); EF, cardiac ejection fraction.

Table 2. Summary of the main results of the clinical trias on HBS.

\section{Intradialytic haemodynamic stability}

Based on the European Best Practice Guidelines (EBPG) for hemodynamic instability (Kooman et al., 2007) the average incidence of hypotensive episodes during dialysis therapy is $20 \%$. In some cohort studies, hypotensive events were observed in up to $33 \%$ of cases during dialysis therapy. Hypotensive episodes during the course of dialysis therapy are closely correlated with morbidity and mortality and play a fundamental role in the development of myocardial and cerebral ischemia. Frequent occurrences of hypotension lead to chronic over-hydration and have a negative impact on the clearance of dissolved substances due to water retention.

The first study on HBS was run by Santoro in 1994 which was addressed to check the feasibility of the system. They included a small sample of five patients in a HD-HBS-HD experimental set-up. The occurrence of dialysis complicated by severe hypotension was 8 in $\mathrm{HD}, 1$ in HBS and 5 in the second HD period.

Subsequently, they did another clinical investigation on 8 hypotension-prone patients in a prospective crossover study including 8 hypotension-prone haemodialysis patients (Santoro et al, 1994). They compared conventional haemodialysis (HD) to the HBS, following a protocol with an HD1-HBS-HD2 sequence, with each treatment period lasting one month. Changes in predialysis to postdialysis systolic arterial pressure were lower in the HBS 
period $(-12.4 \%)$ compared to both HD periods $(-20 \%$ in HD1 and $-17.5 \%$ in HD2; $P<0.05)$, despite comparable total ultrafiltration rates and mean treatment times. A significant reduction in the number of severe hypotensive episodes (HBS: 3, HD1: 26, HD2: 16; $P<0.05$ ) and fewer intradialytic events, such as cramps and nausea, were observed. This resulted in a reduced need for therapeutic isotonic saline in each session (HBS: $60 \mathrm{~mL}, \mathrm{HD}$ : $160 \mathrm{~mL}$, HD2: $95 \mathrm{~mL}$; $P$ <.05).

The first randomised, controlled trial on HBS was published by Ronco (Ronco et al, 2000), who treated 12 hypotension-prone patients with either 2 weeks of HD followed by 2 weeks of HBS or vice versa (6 session per patient and 72 in total). They also observed fewer hypotensive episodes with HBS $(24 / 72$ vs $59 / 72$ in HD; $P<0.001)$. Saline infusion was required in 15 cases during HBS in comparison to 57 cases during HD $(P<0.001)$.

Medium-term treatment with HBS was evaluated in a prospective study published by Basile (Basile et al., 2001). They investigated the efficacy and safety of HBS vs conventional HD in 19 hypotension-prone uraemic patients. After a period of 6 months on HD, patients switched to HBS for 14 to 30 months. A wash-out phase of 4 weeks was followed by a shortterm treatment period of 3 weeks, first with HD and then after wash-out with HBS. The overall occurrence of symptomatic hypotension and muscle cramps was significantly reduced, with a decrease of $34 \%$ and $40 \%$ respectively $(P$-values: $<0.002$ and $<0.02$ respectively). In the short-term part of the study, the vascular refilling (residual $\mathrm{BV} \% / \mathrm{ECV} \%$ ratio) was significantly higher during the HBS treatment.

Several other groups have been shown improvement in haemodialysis-induced hypotension in hypotension-prone patients [Santoro et al., 2002; Franssen et al., 2005; Selby et al., 2006; Moret et al., 2006; Dasselaar et al., 2007; Neshrallah et al; Winkler et al., 2008).

Ambulatory blood-pressure measurement in one prospective trial revealed that during the first 16 hours post-HD, systolic blood pressure was significantly higher with HBS in comparison to conventional HD (Franssen et al., 2005). Other trials showed a significant overall decrease in systolic blood pressure in both groups during the study period $(P=0.005$ vs the baseline) (Deziel et al., 2007). However, the difference between the HD and HBS arms was not significant.

Attempts to correct extracellular fluid volume (ECFV) with aggressive ultrafiltration often leads to intradialytic hypotension. Therefore, it was of interest to see whether HBS treatment could safely reduce ECFV in extracellular fluid-expanded patients (Neshrallah et al., 2008). However, the results of this randomised trial revealed no change with HBS, even after multivariate adjustment.

Bégin et al. investigated whether improvement in hypotension-related events can be explained by changes in dry weight (Begìn et al., 2002). In their prospective trial in 7 hypotension-prone patients, they observed the greatest improvement in event-free sessions (i.e. sessions not requiring therapeutic intervention for hypotension-related signs and symptoms) in patients who had the smallest changes in dry weight. This is supported by other studies, which revealed that HBS was not effective in reducing post-HD dry weight (Fransesen et al, 2005, Dasselaar et al., 2007). A randomised, controlled trial demonstrated that the best responders to HBS treatment were those with higher predialysis systolic bloodpressure values compared to poor responders $(P=0.04)$ (Santoro et al., 2002).

While most data on HBS were obtained from the study of hypotension-prone patients, one trial was especially designed to look at the effects in non-hypotension-prone uraemic patients (McIntyre et al., 2003). During this prospective study, 15 patients received conventional HD over 3 weeks followed by a 2-week wash-out phase and an HBS-treatment 
phase over 3 weeks. There was a reduction in symptomatic episodes (per patient over 3 weeks) from 3 during HD to 0.13 with HBS $(P<0.001)$. The number of treatments affected by a reduction of $>40 \%$ in systolic blood pressure decreased from 1.4 to 0.46 and episodes during which relative blood volume fell by $>10 \%$ were reduced from 6.3 to 1.13 per patient and treatment period $(P<0.001)$. The treatment of 28 hypertensive patients with either standard HD or HBS in a randomised manner showed significantly fewer hypotensive episodes, lower brain natriuretic peptide levels (not significant) and a significant reduction in predialysis blood pressure in the HBS group (Neshrallah et al., 2008).

\section{Pooled analysis about intradialytic cardiovascular stability}

Since, most of the studies, addressed the intradialytic hypotension, we summarized the data about the cardiovascular instability (intradialytic hypotension and weight loss) in the following pooled analysis. We included all the studies of any type (random cross-over, random not cross over and not random), which reported available data in form of percentage of dialysis complicated by hypotensions or average frequency of hypotension events, disregarding this was or was not the primary response variable.

\begin{tabular}{lrr}
$\begin{array}{l}\text { Intradialytic hypotension } \\
\text { Study or Subgroup }\end{array}$ & Weight & $\begin{array}{r}\text { Mean Difference } \\
\text { IV, Random, 95\% Cl }\end{array}$ \\
\hline 1994 Santoro (1) & $5.7 \%$ & $-19.00[-31.21,-6.79]$ \\
1998 Santoro (2) & $6.4 \%$ & $-9.00[-20.12,2.12]$ \\
2000 Ronco & $4.8 \%$ & $-49.00[-62.96,-35.04]$ \\
2001 Basile (3) & $15.2 \%$ & $-10.80[-11.79,-9.81]$ \\
2002 Santoro & $12.5 \%$ & $-10.00[-14.46,-5.54]$ \\
2002 Wolkotte & $9.8 \%$ & $-12.00[-19.02,-4.98]$ \\
2003 Mclntyre & $11.4 \%$ & $-8.00[-13.49,-2.51]$ \\
2005 Franssen & $2.4 \%$ & $-27.00[-48.66,-5.34]$ \\
2006 Moret (4) & $8.4 \%$ & $-8.00[-16.56,0.56]$ \\
2007 Dasselaar & $0.6 \%$ & $-44.70[-93.15,3.75]$ \\
2007 Deziel (5) & $8.4 \%$ & $-1.00[-9.50,7.50]$ \\
2008 Neshrallah & $2.9 \%$ & $-8.00[-27.53,11.53]$ \\
2008 Winkler & $11.6 \%$ & $-7.80[-13.09,-2.51]$ \\
& & \\
Total (95\% Cl) & $100.0 \%$ & $-\mathbf{1 1 . 7 6}[-\mathbf{1 5 . 4 3 , - 8 . 0 9 ]}$ \\
Test for overall effect: Z $6.28(\mathrm{P}<0.00001)$
\end{tabular}

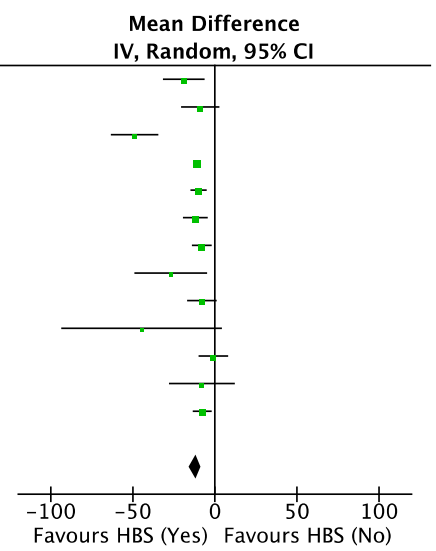

\footnotetext{
(1) Data pooled over A1, A2 study phases

(2) Data pooled over A1, A2 study phases

(3) Medium term study

(4) Data referred to the conventional vs HBS phases

(5) Data referred to 4 weeks recording ( 2 weeks at the beginning and 2 weeks at the end)
}

Fig. 4. Pooled analysis of intradialytic hypotensions. The figure shows the hypotension events expressed as mean \pm SD over the total number of dialysis.

We did not include in the analysis those studies for which confounding factors like hemodiafiltration and/or acetate free biofiltration, cold dialysate temperature if not present both in the intervention and control treatments could interfere with data interpretation.

For each study we extracted the total number of treatments performed both with standard and HBS hemodialysis and the total events (dialysis complicated by hypotensions or major hypotension events) for each one, or the mean $\pm \mathrm{SD}$ hypotension events as reported in the paper. 
Figure 4 shows the results of the pooled analysis about the intradialytic hypotension of the thirteen included studies in the analysis. The reported data refer to 2520 dialysis in HBS against 2130 dialysis in conventional dialysis.

The overall mean difference was nearly $-12 \%$ favoring the HBS treatment with an estimated range between $-15 \%$ and $-8 \%$. The range is almost narrow despite some studies showed wider ranges (Dasselaar et al., 2007).

Discrepancies between the single studies can be partially explained by: a) the difference in within study variance underlying the difference in the sample size (from 8 to 44 recruited patients), b) the difference in the study design (cross-over, parallel group, etc) c) the target population (hypotension prone, non-hypotension prone and hypertensive patients), d) the difference in the between study reflecting the difference in the primary response variable (blood pressure drop, fluid overload) leading sometimes to a bias in the dialysis complicated by hypotension variable, e) the length of follow up ranging from few weeks to two years.

These good results are emphasized by looking at the weight loss during dialysis in the two treatments as reported in Figure 5. The overall result shows a higher weight loss in HBS than in standard treatment equal to $160 \mathrm{~g}$. All the authors reported this behavior even though some were not statistically significant. McIntyre indeed report the interdialytic weight gain, which could not properly reflect the weight loss during the follow-up.

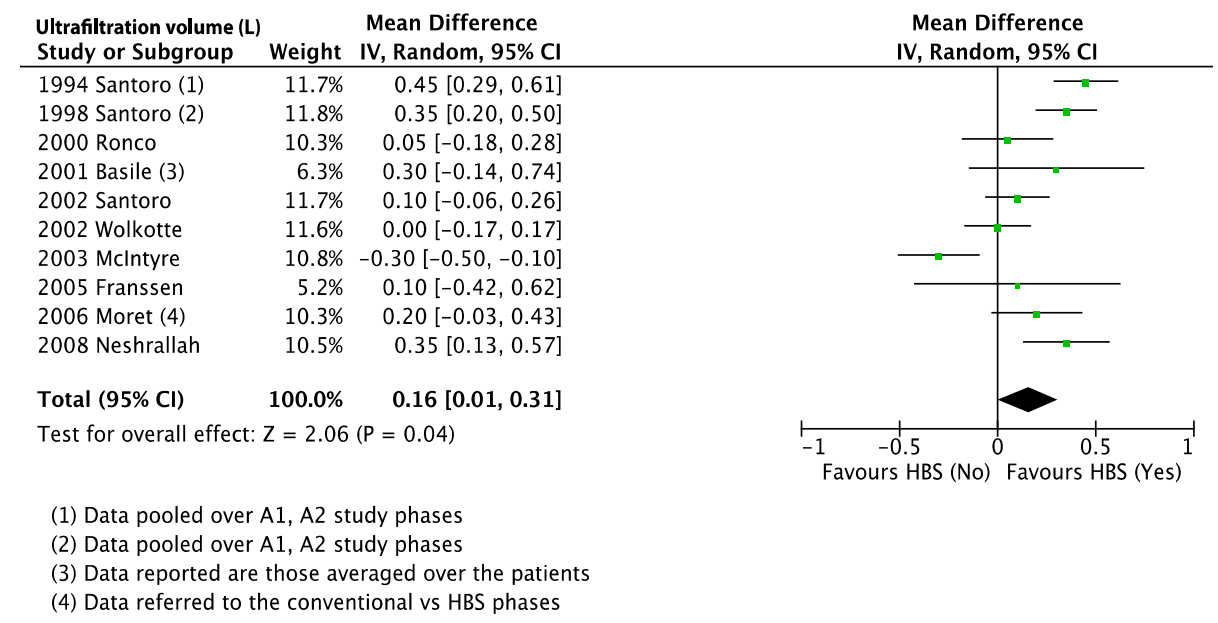

Fig. 5. Body weight loss during dialysis. Data report the pre to post dialysis body weight change during dialysis (in $\mathrm{Kg}$ or L) expressed as mean $\pm \mathrm{SD}$ over the total assessed dialysis.

Different alternatives are available to reduce or prevent the noticeable drop in blood pressure during the extracorporeal therapy. In this context, the time and frequency of dialysis play a significant role, but the time of dialysis cannot be infinitely expanded because of socioeconomic framework conditions. Regulating the blood temperature via dialysate temperature can also have a noticeable positive effect on the blood pressure management. To what extent the efficacy of the therapy is limited because of the higher peripheral overall resistance is the subject of further studies. On-line hemodiafiltration is another established possibility to prevent a drop in blood pressure during blood purification therapy. The high convective rate of this procedure is capable of achieving the stabilisation of the blood 
pressure. However, during the first half of the therapy time with in-line hemodiafiltration, HBS is also characterised by a high convective dialysis rate. The recommended increase of the dialysate calcium concentration to $1.5 \mathrm{mmol} / \mathrm{L}$ should be considered with caution because it may result in a significant elevation of the calcium $x$ phosphate product. HBS works with ultrafiltration control and sodium management to realise better refilling of the intravascular compartment.

The short reaction time of the MiMo (Multi input - Multi output) controller (Figure 2) guarantees the prevention of a hypotensive event or reduces its intensity. The underlying mechanisms should be found both in the fast reaction of the system to rapid blood volume drops and in the pre-set pathway which avoid the achievement of risky patient dependent blood volume thresholds.

\section{Electrolyte implications}

The electrolyte implication of HBS have been included in some of the studies and deeply investigated in one paper by Moret (Moret et al., 2006).

In this study they compared the effect of sodium manual profiling and automatic profiling versus standard treatment on the sodium mass balance measure through its surrogate variable, the ionic mass balance. It is interesting the comparison between standard dialysis prescribed at $140 \mathrm{mMol} / \mathrm{L}$ and biofeedback technologies (HBS and biofeedback on plasma conductivity) prescribed at equivalent values of $14.0 \mathrm{mS} / \mathrm{cm}$. The manual profiling was indeed, prescribed with a linear time course starting at $15.0 \mathrm{mS} / \mathrm{cm}$ and ending at 14.0 $\mathrm{mS} / \mathrm{cm}$. The ionic mass balance in each study session was $423 \pm 166 \mathrm{mMol}, 488 \pm 179 \mathrm{mMol}$ and $409 \pm 109 \mathrm{mMol}$ respectively in standard, HBS and plasma conductivity biofeedback.

Other studies on HBS reported data about the post dialysis natremia. Despite they did not investigated the actual sodium mass removal, they found no differences between standard versus HBS sessions. Santoro in 1998 reported end dialysis natremia equal to $146 \pm 1.5$ $\mathrm{mMol} / \mathrm{L}$ in standard hemodialysis and 146.2 \pm 1.1 in HBS. They did not showed the predialysis natremia then one cannot conclude that the ionic mass balance could have been similar in the two treatments. Moreover, this was a short term study and a potential sodium overload could not have been seen. Subsequently the same group published a multicenter study (Santoro et al, 2002) in which data about the pre and postdialysis natremia were shown. Pre and post-dialysis plasma sodium values were: $138.7 \pm 0.5$ and $141.8 \pm 0.6$ in standard HD and 138.8 \pm .6 and $141.3 \pm 0.7$ in HBS. Moreover, if we consider that actual weight loss, blood flow rate and treatment time were equal in both the treatment, we could argue that the sodium mass balance should have been similar in the two treatment. Similar results in short-term study were reported by Wolkotte (Wolkotte et al, 2002). Pre and Post dialysis sodium levels were 139.8 $\pm 2.5,141.2 \pm 1.8$ in standard HD and 139.6 $\pm 2.4,141.3 \pm 1.8$ in HBS respectively and corresponding to weight loss of $2.4 \pm 0.7$ in HD and $2.5 \pm 0.8$ in HBS. Mid-term results were reported only in the study by Dasselaar (Dasselaar et al., 2007). The follow-up lasted 12 week per group (HD and HBS) and the values were at the end of the follow-up were: $139.2 \pm 2.5,139.8 \pm 2.1$ in HD and 139.8 $\pm 2.2,139.9 \pm 2.1$ in HBS. Then, they observed an increase of $1 \mathrm{mMol} / \mathrm{L}$ in the postdialysis natremia but, the actual wight loss was $2.7 \pm 6.7 \mathrm{~L}$ in HD while $3.1 \pm 6.5 \mathrm{~L}$ in HBS even though not statistically significant.

In conclusion, the several authors who investigated this aspect did not find any potential sodium overload in HBS. This is due to the underlying mathematical sodium kinetics model used to regulate the sodium mass balance in the form of equivalent conductance. 


\section{Cardiac effects of haemodynamic stability}

Cardiac failure and the rate of cardiovascular mortality are extremely high in dialysis patients. One of the major causes of heart failure in these patients is probably recurrent subclinical myocardial ischemia. Selby et al. examined whether this occurs in response to stress of haemodialysis and whether it can be reduced by improved hemodynamic stability with HBS treatment (Selby et al., 2006). Eight hypotension-prone patients were included in a randomised cross-over trial to compare the development of left-ventricular regional-wall motion abnormalities during HBS treatment and standard HD. There were 42 regional-wall motion abnormalities during HD vs 23 during HBS (odds ratio 1.8; 95\% CI: 1.1 to 3.0). The majority of these abnormalities improved in function within 30 minutes after dialysis (Figure 7). At peak stress, ejection fraction was significantly lower during HD $(P=0.043)$. Haemodynamic parameters, such as pulse rate, stroke-volume decrease, cardiac output decrease, peripheral resistance and mean baroflex sensitivity, were all significantly improved during HBS vs HD. We noted comparable results in a retrospective analysis of 18 patients after 48 weeks of HBS treatment (Winkler et al., 2008): ejection-fraction increase, though not significant, and a decrease in left ventricular-mass index $(P<0.05)$. In addition, the use of antihypertensive drugs decreased (Figure 7). Two other groups looked at the effect of HBS treatment on antihypertensive drug use (Dasselaar et al. 2007, Neshrallah et al., 2008). Dasselaar et al. showed that the defined daily dose (DDD) of antihypertensive drugs decreased (not significantly) in the HBS group, whereas it was stable in the control HD arm (Dasselaar et al., 2007). Nesrallah et al. observed no change in antihypertensive drug use in their randomised controlled trial (Neshrallah et al., 2008).
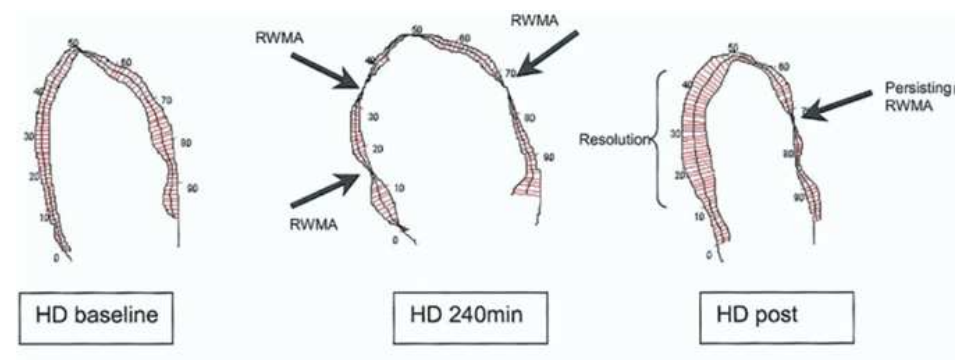

$$
\text { HD baseline }
$$

HD 240min
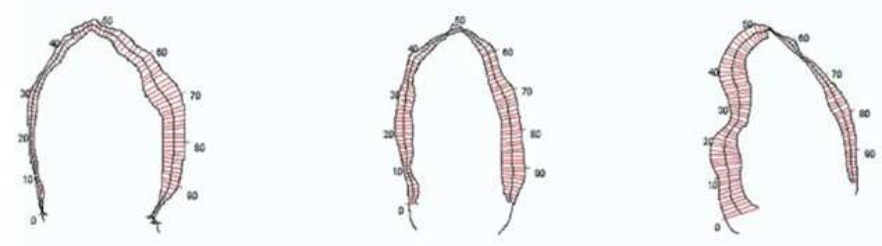

BFD baseline

BFD 240min

BFD post

Fig. 6. Analysis of left ventricular wall motion in one patients during conventional (HD) and biofeedback dialysis (BFD). Arrows indicates the regional wall motion abnormalities which persist even after the end of the treatment (Selby et al., 2006). 


\section{Efficiency of treatment}

Effects of the achieved cardiovascular stability were accompanied by an improved efficiency of treatment. A lower urea rebound was observed during the HBS sessions, resulting in a higher equilibrated Kt/V (eKt/V) as shown by several groups (Ronco et al., 2000, McIntyre et al., 2003, Dasselaar et al., 2007, Neshrallah et al., 2008, Winkler et al. 2008).

In hypotension-prone patients, total urea removed was significantly higher during HBS compared to HD sessions (Ronco et al., 2000). This was also demonstrated for nonhypotension-prone patients. The eKt/V ratio increased from $1.01 \pm 0.03$ to $1.13 \pm 0.03$ with HBS $(P<0.01)$ (McIntyre et al., 2003) In this group of patients, the mass of urea removed increased from 24.9 to $32.7(P<0.01)$.

\section{Interdialytic events}

The effect of HBS on interdialytic symptoms, such as muscle cramps, headache, dizziness, thirst, dyspnoe, angina, vomiting, itching, the need to lie down, anorexia and asthenia, was analysed by Santoro (Santoro et al., 2002) They looked at the number of symptoms between 2 consecutive sessions within the first 6 hours from the end of dialysis (early symptoms) and later until the beginning of the next dialysis session (late symptoms) and observed a $10 \%$ overall reduction $(P<0.001)$ in symptoms after treatment with HBS.

\section{Quality of life}

Déziel et al. investigated the impact of HBS treatment on health-related quality of life (Deziel et al., 2007). They included 44 patients who were partially hypertensive and/or hypotension-prone in a 6-month randomised controlled trial comparing standard HD and HBS. Quality of life was assessed using the Kidney Disease and Quality of Life Short Form (KDQOL-SF) questionnaire. There was a significant improvement in the burden of

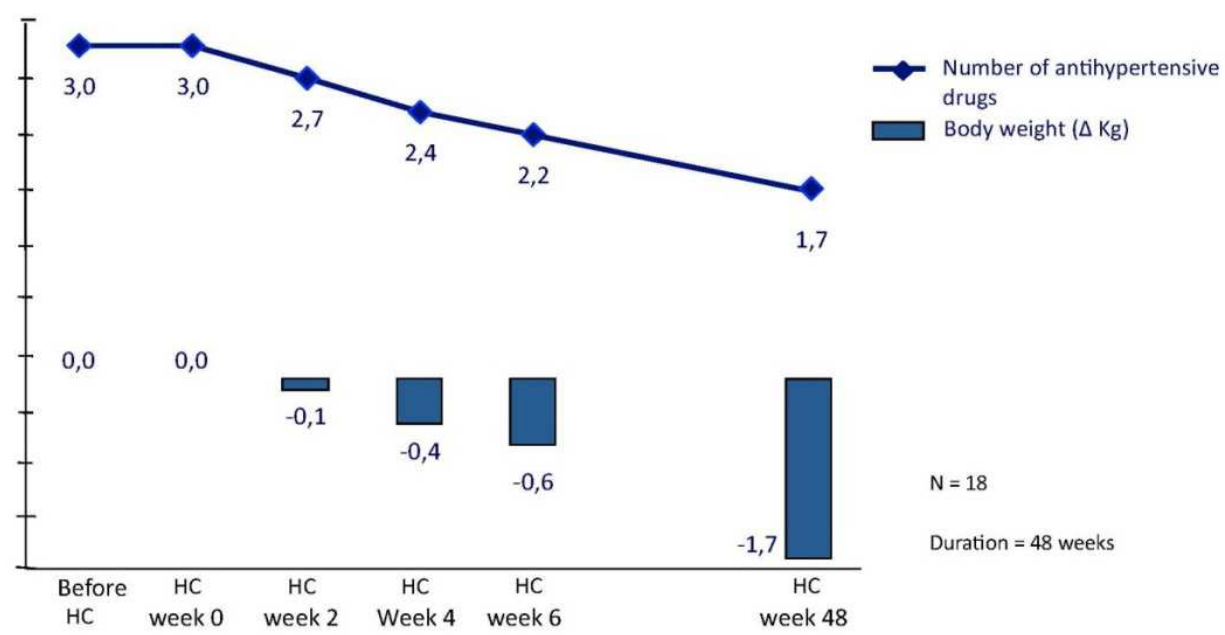

Fig. 7. Decrease of antihypertensive drug and end dialysis body weight over 48 months of follow-up. 
kidney disease score in the HBS group, while there was a decrease in the control group $(P=0.004)$. There was no other significant variation in quality-of-life items during the study. In another randomised trial comparing 6-month HD vs HBS treatment, a validated dialysis-related symptoms questionnaire was used to assess dialysis-related quality of life (Neshrallah et al., 2008). This questionnaire asked patients to rate the frequency and severity of dizziness, fatigue, muscle cramps, and other symptoms. None of these differed significantly between groups over time.

\section{Conclusions}

The growing number of patients with CKD/KDOQI stage 5D is characterised by higher age and increasing comorbidities such as arterial hypertension, diabetes mellitus, arteriosclerosis and atherosclerosis, coronary heart disease as well as peripheral arterial perfusion impairments. In the large majority of patients, age and morbidity-related vascular alterations result in a reduced refilling capacity from the extracellular and intracellular compartment into the intravasal compartment.

The divergence between ultrafiltration and absent refilling can lead to severe hypotensive events during the course of the dialysis. Incidence and intensity of hypotensive complications are correlated with morbidity, frequency of hospitalisation, myocardial and cerebral ischemia and consecutively with mortality.

The complications are preventable by increasing the dialysis time and frequency, decreasing the dialysate temperature, increasing the dialysate calcium concentration and/or with online hemodiafiltration. Nonetheless, dialysis time and frequency are finite, and affects the staff and unit workload, while elevated dialysate calcium concentrations could lead to positive mass balance with cumulative calcium overload exposing the patients to higher risk of valvolar and vascular calcification. Nevertheless, hemodiafiltration, due to the high efficiency and high solute extraction, can yield to transient electrolyte and osmolar disequilibrium (Ursino et al, 1997) opposing to plasma refilling and exposing to higher risk of electrical disequilibrium and cardiac dysrhythmias especially in fragile patients, Then, HBS lends itself as a gentle and effective procedure to improve the refilling capacity, to prevent hypotensive events and to optimize the post-dialysis weight. Under HBS, arterial hypertension was improved, dialysis therapy more effective, the body weight optimised, the myocardial function improved, the risk of intradialytic hypotension lower and the patients quality of life during intradialytic and interdialytic intervals improved.

HBS is a treatment option for elderly, morbid dialysis patients.

\section{References}

Azar T A, Biofeedback systems and adaptive control hemodialysis treatment, Saudi J Kidney Dis Trasplant, 2008, 19, 6, 895-903.

Basile C, Giordano R, Vernaglione L et al. Efficacy and safety of haemodialysis treatment with the Hemocontrol ${ }^{\mathrm{TM}}$ biofeedback system: a prospective medium-term study. Nephrol Dial Transplant 2001; 16: 328-334.

Bégin V, Déziel C, Madore F. Biofeedback regulation of ultrafiltration and dialysate conductivity for the prevention of hypotension during hemodialysis. ASAIO Journal 2002; 48: 312-315. 
Cavalcanti S, Ciandrini A, Severi S, Badiali F, Bini S, Gattiani A, Cagnoli L, Santoro A, Model-based study of the effects of the hemodialysis technique on the compensatory response to hypovolemia, Kidney Int, 2004, 65, 1499-1510.

Dasselaar JJ, Huisman RM, De Jong PE, Burgerhof JGM, Franssen CFM. Effects of relative blood volume-controlled hemodialysis on blood pressure and volume status in hypertensive patients. ASAIO Journal 2007; 53: 357-364.

Dasselaar JJ, Relative blood volume based biofeedback during dialysis, J of renal Care, 2007, XXXIII, 2, 59-65.

Davenport A, Cox C, Thuraisingham R. Achieving blood pressure targets during dialysis improves control but increases intradialytic hypotension. Kidney Int 2008; 73: 759_ 764.

Déziel C, Bouchard J, Zellweger M, Madore F. Impact of Hemocontrol on hypertension, nursing interventions, and quality of life: a randomized controlled trial. Clin J Am Soc Nephrol 2007; 2: 661-668.

Franssen CFM, Dasselaar JJ, Sytsma P, Burgerhof JGM, De Jong PE, Huisman RM. Automatic feedback control of relative blood volume changes during hemodialysis improves blood pressure stability during and after dialysis. Hemodialysis Int 2005; 9: 383-392.

Iseki K, Miyasato F, Tokuyama K, ey al, Low diastolic blood pressure, hypoalbuminemia, and risk of death in a cohort of chronic hemodialysis patients, Kidney Int. 1997, 51, 1212-17.

Kooman J, Basci A, Pizzarelli F, et al EBPG guideline on hemodynamic instability, Nephrol Dial \& Transplan, 2007, 22, S2, i22-i44.

Locatelli F, Buoncristiani U, Canaud B, et al, Haemodialysis with on-line monitoring equipment: tool or toys? Nephrol Dial Tranpslant, 2005, 20, 22-33.

Mancini E, Santoro A, Spongano M, Paolini F, Zucchelli P, Effects of automatic blood volume control over intradialytic hemodynamic stability, Int J Artif Organs, 1995, $18,6,495-498$.

McIntyre CW, Lambie SH, Fluck RJ. Biofeedback controlled hemodialysis (BF-HD) reduces symptoms and increases both hemodynamic tolerability and dialysis adequacy in non-hypotension prone stable patients. Clin Nephrol, 2003; 60: 105-112.

McIntyre CW, Burton JO, Selby NM, Leccisotti L, Korsheed S, Baker C, Camici P, Hemodialysis-induced cardiac dysfunction is associated with an acute reduction in global and segmental myocardial blood flow, Clin J Am Soc, 2008, 3, 19-26.

Moret K, Aalten J, Van den Wall Bake W et al. The effect of sodium profiling and feedback technologies on plasma conductivity and ionic mass balance: a study in hypotension-prone dialysis patients. Nephrol Dial Transplant 2006; 21: 138-144.

Nesrallah GE, Suri RS, Thiessen-Philbrook H, Heidenheim P, Lindsay RM. Can extracellular fluid volume expansion in hemodialysis patients be safely reduced using the Hemocontrol biofeedback algorithm? A randomized trial. ASAIO Journal 2008; 54: 270-274.

Paolini F, Bosetto A, Biofeedback system architecture, Adv in Renal Repl Therapy, 1999, 6, 3, 255-264.

Pastore C, Ruggeri G, Pastore A, Siliberto P, Cristofaro V, Daily use of the physio dialysis system: long-term experience, EDTNA/ERCA J, 2002, XXVIII, 2, 16-20.

Port, FK, Hulbert-Shearon TE, Wolfe RA, et al., Predialysis blood pressure and mortality risk in a national sample of maintenance hemodialysis patients, Am J Kidney Dis, 1999, 33 (3), 507-517. 
Ronco C, Brendolan A, Milan M, Rodeghiero MP, Zanella M, La Greca G. Impact of biofeedback-induced cardiovascular stability on hemodialysis tolerance and efficiency. Kidney Int 2000; 58: 800-808.

Santoro A, Spongano M, Mancini E, Rossi M, Paolini F, Zucchelli P, Parameter estimator and adaptive controller to regulate intradialytic blood volume trends, Proceed of 32nd Congress of Italian Society of Nephrology,1992

Santoro A, Mancini E, Paolini F, Spongano M, Zucchelli P, Automatic Control of Blood Volume trends during Hemodialysis, ASAIO J, 1994, 40, M419-M422.

Santoro A, On-Line monitoring, Nephrol Dial \& Transplant, 1995, 10, 615-618.

Santoro A., Mancini E., Paolini F., Zucchelli P., Blood volume monitoring and control, Nephrol Dial \& Transplant, 1996 11, S2, 42-47.

Santoro A, Clinical significance of intradialytic blood volume monitoring, Int J Artif Organs, 1997, 20, 1, 1-6.

Santoro A, Mancini E, Paolini F, Cavicchioli G, Bosetto A, Zucchelli P. Blood volume regulation during hemodialysis. Am J Kidney Dis 1998; 32: 739-748.

Santoro A, Mancini E, Zucchelli, Ultrafiltration behaviour with different dialysis schedules, Nephrol Dial \& Transplant, 1998, 13, S6, 55-61.

Santoro A, Mancini E, Blood volume monitoring systems and biofeedback, in Ronco C, La Greca, eds Hemodialysis Technology, Contrib to Nephrol, 2002, 137, 233-244.

Santoro A, Mancini E, Basile C et al. Blood volume controlled hemodialysis in hypotensionprone patients: a randomized, multicenter controlled trial. Kidney Int 2002; 62: 1034-1045.

Santoro A, Mambelli E, Canova C, Lopez A, Sestigiani E, Mancini E, Biofeedback dialysis, J Nephrol, 2003, 16, S7, S48-S56.

Santoro A, Ferramosca E, Mancini E, Biofeedback Driven Dialysis: where are we? In: Ronco C, Cruz DN (eds): Hemodialysis - from basic research to clinical trials. Contrib Nephrol. Basel, Karger 2008; 161: 199-209.

Selby NM, Lambie SH, Camici PG, Baker CS, McIntyre CW, Occurrence of regional left ventricular dysfunction in patients undergoing standard and biofeedback dialysis, Am J Kidney Dis, 2006, 47, 5, 830-841.

Severi S, Ciandrini A, Grandi E, Cavalcanti S, Bini S, Badiali F, Gattiani A, Cagnoli L, Cardiac response to hemodialysis with different cardiovascular tolerance: heart rate variability and QT interval analysis, Hemod Int, 2006, 10, 287-293.

Sohji T, Tsubakihara Y, Masamitsu F, et al, Hemodialysis-associated hypotension as an independent risk factor for two-years mortality in hemodialysis patients. Kidney Int. 2004, 66, 1212-20.

Tisler A, Akocsi K, Borbas B, et al, The effect of frequent or occasional dialysis-associated hypotension on survival of patients on maintenance hemodialysis, Nephrol Dial \& Transplant, 2003, 18, 2601-05.

Winkler RE, Pätow W, Ahrenholz P. Blood volume monitoring. In: Ronco C, Cruz DN (eds): Hemodialysis - from basic research to clinical trials. Contrib Nephrol. Basel, Karger 2008; 161: 119-124.

Wolkotte C, Hassell DR, Moret K, Gerlag PG, van den Wall Bake AW, van der Sande FM, Blood volume control biofeedback and dialysis-induced symptomatology, Nephron, 2002, 92, 605-609.

Zucchelli P, Santoro A, Dry weight in hemodialysis: volemic control, Semin Nephrol, 2001, 21, 3, 286-290.

Ursino M, Innocenti M. Mathematical investigation of some physiological factors involved in hemodialysis hypotension. Artif Organs. 1997, 21(8), 891-902. 


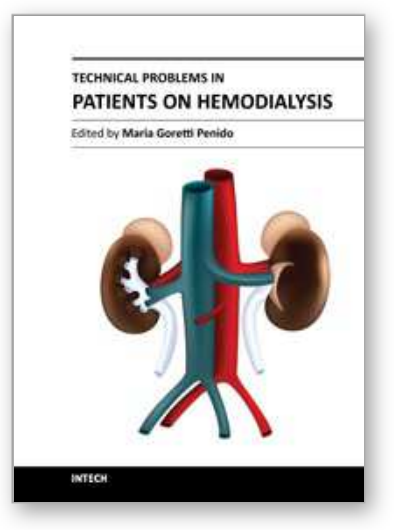

\author{
Technical Problems in Patients on Hemodialysis \\ Edited by Prof. Maria Goretti Penido
}

ISBN 978-953-307-403-0

Hard cover, 312 pages

Publisher InTech

Published online 07, December, 2011

Published in print edition December, 2011

This book provides an overview of technical aspects in treatment of hemodialysis patients. Authors have contributed their most interesting findings in dealing with hemodialysis from the aspect of the tools and techniques used.Each chapter has been thoroughly revised and updated so the readers are acquainted with the latest data and observations in the area, where several aspects are to be considered. The book is comprehensive and not limited to a partial discussion of hemodialysis. To accomplish this we are pleased to have been able to summarize state of the art knowledge in each chapter of the book.

\title{
How to reference
}

In order to correctly reference this scholarly work, feel free to copy and paste the following:

Roland E. Winkler, Fabio Grandi and Antonio Santoro (2011). Blood Volume Regulation, Technical Problems in Patients on Hemodialysis, Prof. Maria Goretti Penido (Ed.), ISBN: 978-953-307-403-0, InTech, Available from: http://www.intechopen.com/books/technical-problems-in-patients-on-hemodialysis/blood-volume-regulation

\section{INTECH}

open science | open minds

\author{
InTech Europe \\ University Campus STeP Ri \\ Slavka Krautzeka 83/A \\ 51000 Rijeka, Croatia \\ Phone: +385 (51) 770447 \\ Fax: +385 (51) 686166 \\ www.intechopen.com
}

\author{
InTech China \\ Unit 405, Office Block, Hotel Equatorial Shanghai \\ No.65, Yan An Road (West), Shanghai, 200040, China \\ 中国上海市延安西路65号上海国际贵都大饭店办公楼 405 单元 \\ Phone: +86-21-62489820 \\ Fax: $+86-21-62489821$
}


(C) 2011 The Author(s). Licensee IntechOpen. This is an open access article distributed under the terms of the Creative Commons Attribution 3.0 License, which permits unrestricted use, distribution, and reproduction in any medium, provided the original work is properly cited. 